\title{
ПРОФИЛЬ ПАЦИЕНТОВ, НАПРАВЛЯЕМЫХ В ЦЕНТР ОСТЕОПОРОЗА МОСКОВСКОЙ ОБЛАСТИ
}

\author{
Полякова Е.Ю., Крюкова И.В., Красулина К.А., Древаль А.В.
}

ГБУЗ МО «Московский областной научно-исследовательский клинический институт им. М.Ф. Владимирского», Москва

ЦЕЛЬ: проанализировать профиль пациентов, направляемых в Центр остеопороза ГБУЗ МО МОНИКИ им. М.Ф. Владимирского из ЛПУ Московской области для дальнейшей оптимизации помощи данному контИнгентУ больных.

МАТЕРИАЛЫ И МЕТОДЫ: проведен анализ 1940 пациентов (1873 женщины, 67 мужчин), направленных на двухэнергетическую рентгеновскую абсорбциометрию (ДРА) и/или специализированный прием по остеопорозу. В исследование включались все последовательные пациенты, обратившиеся за период с 01.01.2019 по 31.12.2019 года.

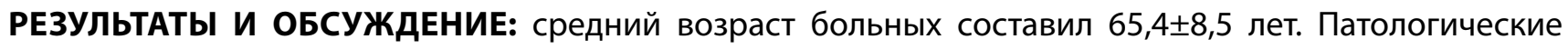
переломы в анамнезе были у 540 пациентов (27,8\%, 527 женщин, 13 мужчин). Участковым врачом направлен только 1 человек (0,1\%), другими специалистами - 1709 (88,1\%), обратились самостоятельно 230 (11,8\%). Цель направления в Центр остеопороза: проведение только ДРА - 2,5\%; ДРА и назначение терапии - 60,9\%; диагностика остеопороза и назначение лечение с данными ДРА, выполненной в другом учреждении - 0,2\%; дифференциальная диагностика остеопороза - 0,2\%; коррекция ранее назначенного лечения - 10,1\%; плановый визит, назначенный специалистом Центра остеопороза - 23\%; цель четко не указана в $3,1 \%$ случаев.

Риск переломов по FRAX рассчитывался у нелеченных больных ( $\mathrm{n}=1277)$. Средний риск основных осте-

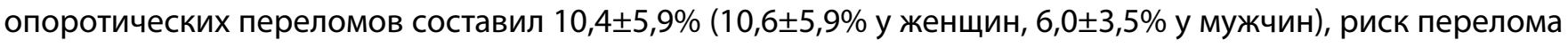

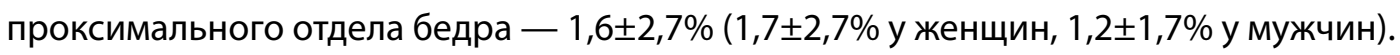

Наименьшее значение T/Z-критерия выявлялось: в позвоночнике у 1355 человек (69,8\%), шейке бедра - y $576(29,7 \%)$, предплечье - у 9 (0,5\%). В группе больных с риском основныхпереломов по FRAX $<20 \%$

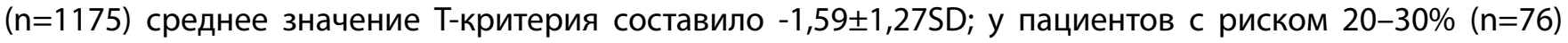
$-2,9 \pm 0,9 S D$ и $>30 \%(n=17)-3,35 \pm 1,32 S D(p<0,001)$. У лиц с риском основных переломов $<20 \%$ остеопороз диагностирован в 33\% случаев ( $\mathrm{n}=388)$, а у пациентов с риском $>20 \%-$ в 100\%. У больных с риском перелома проксимального отдела бедра<3\% остеопороз выявлен в $27 \%$ случаев, с риском >3\% - в 95\%.

В возрастной группе женщин моложе 50 лет остеопороз выявлен в 22,2\% случаев, в группе 50-64 лет в 47,4\% и в возрасте 65 лет и старше - в 60,7\%. Отмечено значимое снижение Т-критерия у женщин 65 лет и старше по сравнению с группой 50-64 лет ( $<<0,001)$.

По результатам ДРА остеопороз впервые выявлен у 400 человек (20,6\%), остеопения - у 476 (24,5\%), заподозрено другое заболевание скелета - у 2 (0,1\%), не выявлено костной патологии - у 360 (18,6\%).

Ранее диагноз остеопороза установлен у 702 пациентов (36,2\%), из них подтвержден в 90\% случаев $(n=632)$, остеопения - в 8,4\% ( $n=59)$, остеопороз не подтвержден - в 1\% ( $n=7)$, выявлено другое заболевание - в 0,4\% $(n=3)$.

Анализ заключений специалиста показал, что из всех больных рекомендовано назначить терапию остеопороза 480 пациентам, продолжить прием ранее используемых препаратов - 396, изменить тактику лечения - 183, отменить терапию - 27, что составило $55,9 \%$, тогда как в $44,1 \%$ случаев показаний к назначению терапии остеопороза не было ( $n=854)$.

ВЫВоды: для выявления пациентов с высокой вероятностью переломов необходим скрининг с использованием алгоритма FRAX. Направление на ДРА и назначение терапии должно проводиться с учетом индивидуального риска переломов. 